\title{
Kinetically Controlled Separation of Cadmium(II) from Zinc(II) with Dithizone in the Presence of Nitrilotriacetic Acid
}

\author{
Hideyuki ITABaShI, ${ }^{\dagger}$ Masaki YoshIDA, and Hiroshi Kawamoto \\ Department of Applied Chemistry, Faculty of Engineering, Gunma University, Kiryu, Gunma 376-8515, Japan
}

\begin{abstract}
The extraction rates of cadmium(II) and zinc(II) with dithizone $\left(\mathrm{H}_{2} \mathrm{dz}\right)$ in the presence of nitrilotriacetic acid (NTA) were measured, and the possible kinetic separation of cadmium(II) from zinc(II) was investigated. Upon the addition of NTA, the difference in the extraction rate between cadmium(II) and zinc(II) became large. Based on the observed rate constant under the condition $[\mathrm{NTA}]=1 \times 10^{-2} \mathrm{~mol} \mathrm{dm}^{-3},\left[\mathrm{H}_{2} \mathrm{dz}\right]_{\text {org }}=1 \times 10^{-3} \mathrm{~mol} \mathrm{dm}^{-3}$, and $\mathrm{pH}=7.0$, the shaking time required for the quantitative separation of cadmium(II) from zinc(II) was calculated to be between 326 and $995 \mathrm{~s}$. The experimental results agreed with the prediction, and the quantitative separation of cadmium(II) from zinc(II) was performed within the above-mentioned range of shaking times.
\end{abstract}

(Received July 11, 2001; Accepted September 7, 2001)

The separation of cadmium(II) from zinc(II) is extremely important from both industrial and environmental viewpoints, because the toxicity of cadmium(II) is remarkably larger than that of zinc(II). The extraction of cadmium(II) and zinc(II) with 3-mercapto-1,5-diphenylformazan (dithizone) has been widely used for analytical purposes. ${ }^{1}$ However, since the extraction constants $\left(K_{\mathrm{ex}}\right)$ for cadmium(II) and zinc(II) with dithizone are almost the same $\left(\log K_{\text {ex }}=2.14\right.$ for cadmium(II), 2.3 for zinc(II)), ${ }^{2}$ their mutual separation with dithizone in the equilibrium state is a difficult task. The kinetic separation of cadmium(II) from zinc(II) using only dithizone also seems to be difficult, because the extraction rate for cadmium(II) with dithizone $\left(1.6 \times 10^{7} \mathrm{~mol}^{-1} \mathrm{~s}^{-1}\right)$ is close to that for zinc(II) $(6.9 \times$ $\left.10^{6} \mathrm{~mol}^{-1} \mathrm{~s}^{-1}\right){ }^{3}$ In previous work, the back-extraction rates of bis(dithizonato)zinc(II) and bis(dithizonato)cadmium(II) were measured, and the possibility of the mutual separation of cadmium(II) from zinc(II) using the back-extraction process has been considered. ${ }^{4,5}$ Taking note of the difference in the backextraction rate, the kinetic separation of cadmium(II) from zinc(II) using a back-extraction procedure could be devised. ${ }^{5}$ However, in this case, the procedure was somewhat tedious because it was necessary to transfer the solution into another separatory funnel. If a quantitative separation can be achieved using only a forward-extraction process, the method will become more convenient.

By the way, it is known that the forward-extraction rate for some metal ions with dithizone is reduced by adding citrate, tartarate, and other auxiliary complexing agents. ${ }^{6}$ By using the effect of an auxiliary complexing agent, the kinetically controlled separation of cadmium(II) from zinc(II) seems to be possible. In this paper, nitrilotriacetic acid (NTA) was selected as the complexing agent based on the stability constant of metal complexes. The extraction rates of cadmium(II) and zinc(II) with dithizone in the presence of NTA were measured, and the possibility of the quantitative separation of cadmium(II) from zinc(II) with dithizone using the forward-extraction process was investigated.

\section{Experimental}

\section{Reagents}

Dithizone and metal salts were obtained from Wako Pure Chemicals, and were used without further purification. A stock solution of NTA was prepared by dissolving appropriate amounts of nitrilotriacetic acid disodium salt (Aldrich Chemical Co.) in water. The water used to prepare the reagent was obtained from a Milli-Q water-purification system (Millipore Co.).

\section{Apparatus}

A Hitachi (Model Z-6100) atomic absorption spectrophotometer equipped with a hollow cathode lamp (Hamamatsu Photonics) was used for the determination of metal ions. A Fisher Scientific (Accumet pH meter 15) and an Iwaki (KM-type) shaker were used for $\mathrm{pH}$ measurements and shaking the separatory funnels, respectively.

\section{Procedure}

Twenty cubic centimeters of an aqueous solution containing $1.0 \times 10^{-5} \mathrm{~mol} \mathrm{dm}^{-3}$ cadmium(II) and zinc(II), $0.1 \mathrm{~mol} \mathrm{dm}^{-3}$ $\mathrm{NaClO}_{4}, 1 \times 10^{-2} \mathrm{~mol} \mathrm{dm}{ }^{-3} 3$-morpholinopropanesulfonic acid buffer solution $(\mathrm{pH}=7.0)$ and $2.0 \times 10^{-5}-5.0 \times 10^{-2} \mathrm{~mol} \mathrm{dm}^{-3}$ NTA were taken into a separatory funnel. After an equal volume of chloroform containing $1.0 \times 10^{-3} \mathrm{~mol} \mathrm{dm}^{-3}$ dithizone was added, the mixture was shaken vigorously (shaking speed; 360 strokes $\mathrm{min}^{-1}$ ) for a definite time. After the phases were allowed to separate, the concentration of a metal ion in the aqueous phase was measured with an atomic absorption spectrophotometer. The $\mathrm{pH}$ was also measured by using a glass electrode. All experiments were carried out at room temperature (ca. $293 \mathrm{~K})$.

\footnotetext{
$\doteqdot$ To whom correspondence should be addressed.
} 
Table $1 \quad \log K_{\mathrm{CdL}}$ and $\log K_{\mathrm{ZnL}}$ values

\begin{tabular}{lccl}
\hline Complexing agent & $\log K_{\text {CdL }}$ & $\log K_{\text {ZnL }}$ & Ref. $^{a}$ \\
\hline DTPA & 19.0 & 18.29 & p.281(Vol.1) \\
CDTA & 19.84 & 19.35 & p.239(Vol.1) \\
EDTA & 16.36 & 16.44 & p.208(Vol.1) \\
EGTA & 16.5 & 12.6 & p.271(Vol.1) \\
HEDTA & 13.1 & 14.6 & p.201(Vol.1) \\
NTA & 9.78 & 10.66 & p.142(Vol.1) \\
DHEG & 4.80 & 5.37 & p.105(Vol.1) \\
IDA & 5.71 & 7.24 & p.118(Vol.1) \\
Citric acid & 3.75 & 4.98 & p.163(Vol.3) \\
Oxalic acid & 2.75 & 3.43 & p.94(Vol.3) \\
\hline
\end{tabular}

a. A. E. Martell and R. M. Smith "Critical Stability Constants", 1974, Plenum Press, New York.

DTPA, diethylenetriamine- $N, N, N^{\prime}, N^{\prime \prime}, N^{\prime \prime}$-pentaacetic acid; CDTA, trans-1,2-diaminocyclohexane- $N, N, N^{\prime}, N^{\prime}$-tetraacetic acid; EDTA, ethylenediamine- $N, N, N^{\prime}, N^{\prime}$-tetraacetic acid; EGTA, $O, O^{\prime}$-bis(2 aminoethyl)ethyleneglycol- $N, N, N^{\prime}, N^{\prime}$-tetraacetic acid; HEDTA, $N$-(2hydroxyethyl)ethylenediamine- $N, N^{\prime}, N^{\prime}$-triacetic acid; DHEG, $N, N$ bis(2-hydroxyethyl)glycine; IDA, iminodiacetic acid.

\section{Results and Discussion}

\section{Selection of auxiliary complexing agent}

The auxiliary complexing agent for the separation of cadmium(II) from zinc(II) was selected based on the following consideration.

Complexation of a metal ion $\left(\mathrm{M}^{2+}, \mathrm{M}=\mathrm{Cd}\right.$ or $\left.\mathrm{Zn}\right)$ with an auxiliary complexing agent $\left(\mathrm{L}^{n-}\right)$ in the aqueous phase proceeds according to

$$
\mathrm{M}^{2+}+\mathrm{L}^{n-} \rightleftharpoons \mathrm{ML}^{(n-2)-},
$$

for which the equilibrium constant $\left(K_{\mathrm{ML}}\right)$ is defined as

$$
K_{\mathrm{ML}}=\frac{k_{+}}{k_{-}},
$$

where $k_{+}$and $k_{-}$are the forward and reverse reaction-rate constants of Eq. (1), respectively. On the other hand, the extraction reaction of $\mathrm{ML}^{(n-2)-}$ with dithizonato anion $\left(\mathrm{Hdz}^{-}\right)$is assumed to proceeds as

$$
\begin{aligned}
& \mathrm{ML}^{(n-2)-} \longrightarrow \mathrm{M}^{2+}+\mathrm{L}^{n-} \\
& \mathrm{M}^{2+}+2 \mathrm{Hdz}^{-} \longrightarrow \mathrm{M}(\mathrm{Hdz})_{2} \\
& \mathrm{M}(\mathrm{Hdz})_{2} \longrightarrow \mathrm{M}(\mathrm{Hdz})_{2, \mathrm{org}}
\end{aligned}
$$

where org denotes the organic phase. Assuming that the ratedetermining step in the above extraction reaction is the dissociation reaction of $\mathrm{ML}^{(n-2)-}$ shown in Eq. (3), the extraction rate would greatly depend on the $k_{-}$value. In the case of the separation of cadmium(II) from zinc(II), where only cadmium(II) is extracted into the organic phase by using the difference in the extraction rate, separation becomes possible

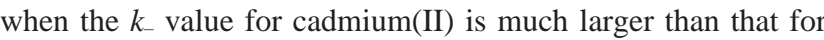
zinc(II). On the other hand, the $k_{+}$value for cadmium(II) is larger than that for zinc(II), because the rate constant for the substitution of innersphere water molecules of cadmium(II) ion is larger than that of zinc(II) ion. ${ }^{7}$ Therefore, if the ligand which forms a more stable complex with zinc(II) than with

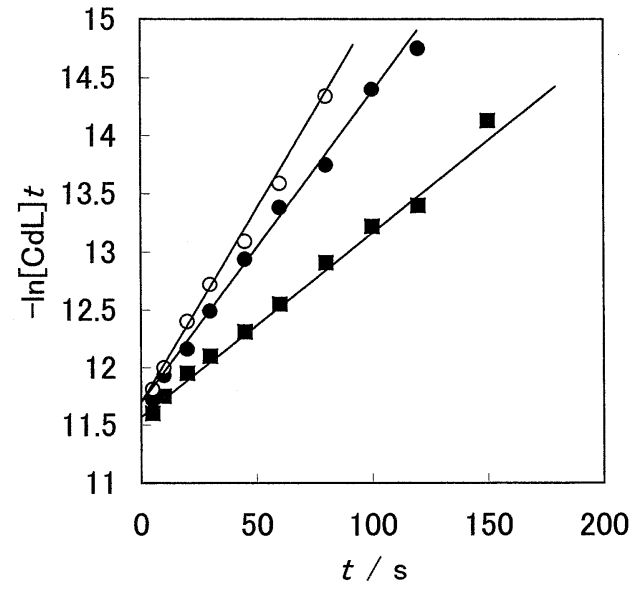

Fig. 1 Plots of $-\ln [\mathrm{CdL}]_{t}$ against shaking time $(t)$. Concentration of NTA: (०), $1.0 \times 10^{-4} \mathrm{~mol} \mathrm{dm}^{-3} ;(\bullet), 5.0 \times 10^{-3} \mathrm{~mol} \mathrm{dm}^{-3} ;(\boldsymbol{\square}), 1.0 \times$ $10^{-2} \mathrm{~mol} \mathrm{dm}^{-3}$.

cadmium(II) is selected as an auxiliary complexing agent, i.e. $K_{\mathrm{ZnL}}>K_{\mathrm{CdL}}$, the $k_{-}$value for cadmium(II) becomes much larger than that for zinc(II). The equilibrium constants $\left(K_{\mathrm{ML}}\right)$ for the complexation of cadmium(II) and zinc(II) with some complexing agents are given in Table 1. As shown in Table 1, HEDTA, NTA, DHEG, IDA, citric acid and oxalic acid satisfy the above-mentioned condition among these complexing agents. However, because HEDTA has a large $K_{\mathrm{ML}}$ value, cadmium(II) ions will be masked by adding HEDTA, and their extraction would become incomplete. On the other hand, if DHEG, IDA, citric acid and oxalic acid are selected, a quantitative complexation of metal ions would seem to be difficult because the values of $K_{\mathrm{ML}}$ are rather small. Therefore, NTA, having a moderate complexing ability, was selected as an auxiliary complexing agent in the present work.

\section{Extraction rates of cadmium(II) and zinc(II) with dithizone in} the presence of NTA

To evaluate the effect of the addition of NTA, the observed rate constants for the extraction of cadmium(II) and zinc(II) in the presence of NTA were measured. Assuming that the extraction rate of a metal ion with dithizone is first order with respect to the concentration of the metal-NTA complex (ML), the reaction rate is defined as

$$
-\frac{\mathrm{d}[\mathrm{ML}]}{\mathrm{d} t}=k_{\mathrm{obsd}}[\mathrm{ML}]
$$

where $t$ and $k_{\mathrm{obsd}}$ denote the shaking time and the observed rate constant, respectively. Integration results in

$$
-\ln [\mathrm{ML}]_{t}=-\ln [\mathrm{ML}]_{t=0}+k_{\mathrm{obsd}} t .
$$

According to Eq. (7), a plot of $-\ln [\mathrm{ML}]_{t}$ against $t$ should give a straight line having a slope of $k_{\text {obsd. }}$. Plots of $-\ln [\mathrm{CdL}]_{t}$ against $t$ in the presence of NTA are shown in Fig. 1, where each plot falls on a straight line, showing that Eq. (7) is valid. Plots of $-\ln [\mathrm{ZnL}]_{t}$ against $t$ also gave straight lines. Plots of $\log k_{\text {obsd }}$ against $\log [\mathrm{NTA}]$ under the condition that $\left[\mathrm{H}_{2} \mathrm{dz}\right]_{\text {org }}=1.0 \times 10^{-3}$ mol dm ${ }^{-3}$ and $\mathrm{pH}=7.0$ are shown in Fig. 2. The $\log k_{\text {obsd }}$ value of cadmium(II) is almost constant in the NTA concentration range of $5.0 \times 10^{-5}$ to $5.0 \times 10^{-3} \mathrm{~mol} \mathrm{dm}^{-3}$, whereas that of zinc(II) decreases with an increase in the concentration of NTA. 


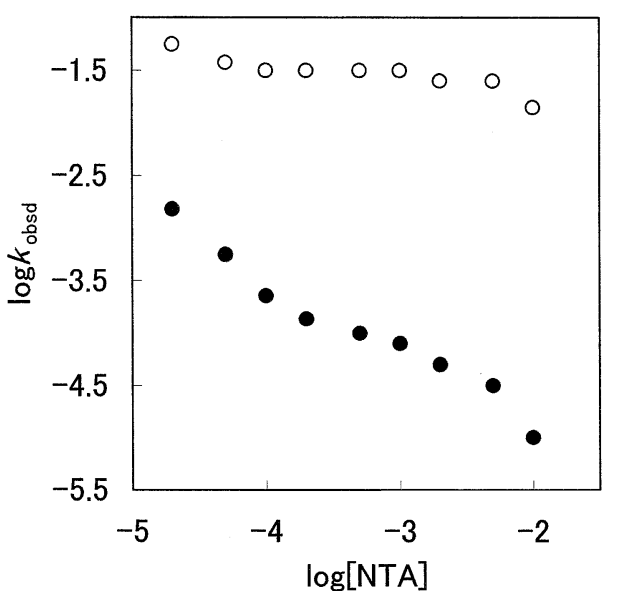

Fig. 2 Plots of $\log k_{\text {obsd }}$ against $\log [\mathrm{NTA}$ ]. ( ( ), cadmium(II); zinc(II). $\left[\mathrm{H}_{2} \mathrm{dz}\right]_{\text {org }}: 1.0 \times 10^{-3} \mathrm{~mol} \mathrm{dm}^{-3} ; \mathrm{pH} 7.0$.

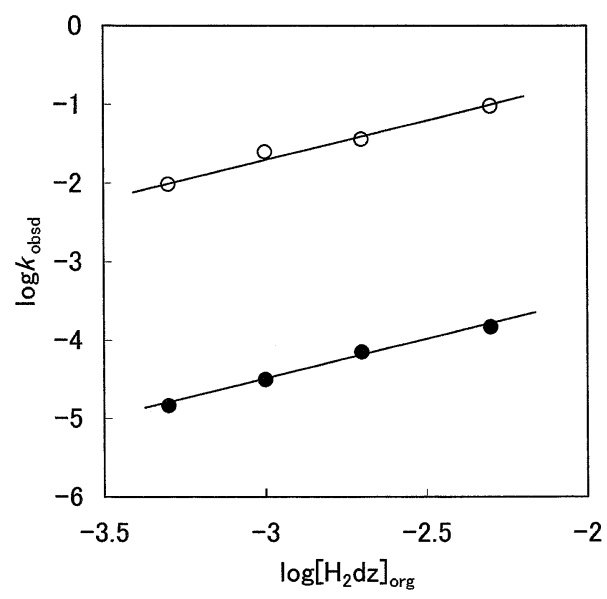

Fig. 3 Plots of $\log k_{\text {obsd }}$ against $\log \left[\mathrm{H}_{2} \mathrm{dz}\right]_{\text {org. }}$ ( o ), cadmium(II); (•), zinc(II). [NTA]: $5.0 \times 10^{-3} \mathrm{~mol} \mathrm{dm}^{-3} ; \mathrm{pH} 7.0$.

Therefore, the difference in the $k_{\mathrm{obsd}}$ values of cadmium(II) and zinc(II) increases with increasing the concentration of NTA. Although it is not presently fully understood why only the extraction rate of zinc(II) decreases with increasing the NTA concentration, the addition of NTA advantageously acts on the kinetic separation of cadmium(II) from zinc(II).

Effects of the dithizone concentration and $\mathrm{pH}$ for the separation of cadmium(II) from zinc(II)

The effect of the dithizone concentration was examined within the range $5 \times 10^{-4}-5 \times 10^{-3} \mathrm{~mol} \mathrm{dm}^{-3}$ at $[\mathrm{NTA}]=5.0 \times 10^{-3} \mathrm{~mol}$ $\mathrm{dm}^{-3}, \mathrm{pH}$ 7.0. Plots of $\log k_{\text {obsd }}$ against $\log \left[\mathrm{H}_{2} \mathrm{dz}\right]_{\text {org }}$ are shown in Fig. 3. The extraction rates increase with increasing $\left[\mathrm{H}_{2} \mathrm{dz}\right]_{\text {org }}$, and plots having a slope of unity show that the extraction rates are first order with respect to $\left[\mathrm{H}_{2} \mathrm{dz}\right]_{\text {org }}$. Although the difference in the extraction rates between cadmium(II) and zinc(II) was almost constant in the examined $\left[\mathrm{H}_{2} \mathrm{dz}\right]_{\text {org }}$ range, the extraction of cadmium(II) was not quantitative when $\left[\mathrm{H}_{2} \mathrm{dz}\right]_{\text {org }}$ was lower than $5 \times 10^{-4} \mathrm{~mol} \mathrm{dm}^{-3}$. Therefore, $1.0 \times 10^{-3} \mathrm{~mol} \mathrm{dm}^{-3}\left[\mathrm{H}_{2} \mathrm{dz}\right]_{\text {org }}$ was chosen for the procedure. The effect of the extraction $\mathrm{pH}$ was examined within the range 5.0-8.0. Plots of $\log k_{\text {obsd }}$ against $\mathrm{pH}$ are shown in Fig. 4. The extraction rates increase with increasing $\mathrm{pH}$, and plots having a slope of unity show that

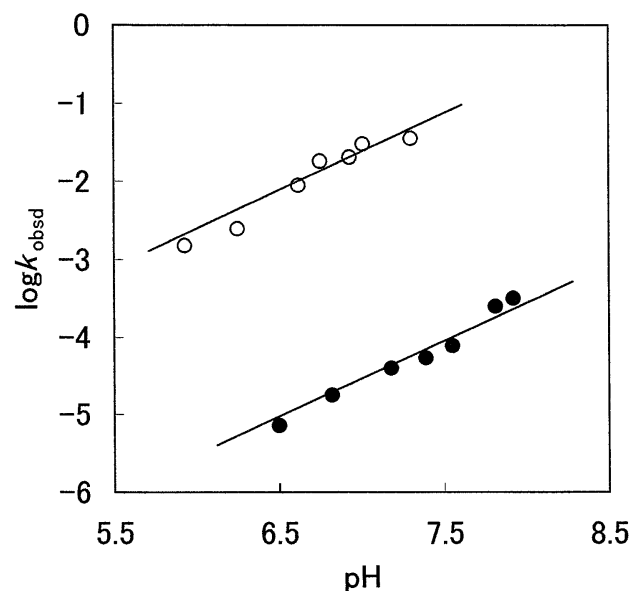

Fig. 4 Plots of $\log k_{\text {obsd }}$ against pH. (०), cadmium(II); (•) zinc(II). [NTA]: $5.0 \times 10^{-3} \mathrm{~mol} \mathrm{dm}^{-3} ;\left[\mathrm{H}_{2} \mathrm{dz}\right]_{\text {org }}: 1.0 \times 10^{-3} \mathrm{~mol} \mathrm{dm}^{-3}$.

the extraction rates are minus first order with respect to $\left[\mathrm{H}^{+}\right]$. Although the extraction rate difference between cadmium(II) and zinc(II) was almost constant in the examined $\mathrm{pH}$ range, the extraction of cadmium(II) was not quantitative when the $\mathrm{pH}$ was lower than 6 . Therefore, $\mathrm{pH}=7.0$ was chosen for the procedure.

Calculation of the shaking time for the quantitative separation of cadmium(II) from zinc(II)

Based on the $k_{\text {obsd }}$ value, the shaking time required for the quantitative separation of cadmium(II) from zinc(II) was calculated as follows.

Equation (7) is rewritten as

$$
\frac{[\mathrm{ML}]_{t=0}}{[\mathrm{ML}]_{t}}=\mathrm{e}^{k_{\text {obsat }}}
$$

The mass balance in the extraction system gives

$$
[\mathrm{ML}]_{t=0}=\left[\mathrm{M}(\mathrm{Hdz})_{2}\right]_{\mathrm{org}, t}+[\mathrm{ML}]_{t}
$$

From Eqs. (8) and (9), the distribution ratio $\left(D^{\mathrm{M}}=\right.$ $\left.\left[\mathrm{M}(\mathrm{Hdz})_{2}\right]_{\mathrm{org}, t}[\mathrm{ML}]_{t}^{-1}\right)$ can be written as

$$
D^{\mathrm{M}}=\frac{[\mathrm{ML}]_{t=0}}{[\mathrm{ML}]_{t}}-1=\mathrm{e}^{k_{\mathrm{osad}}}-1
$$

It is assumed that $D^{\mathrm{Cd}} \geqq 100$ and $D^{\mathrm{Zn}} \leqq 0.01$ is the condition for the quantitative separation of cadmium(II) from zinc(II), Eq. (10) leads to the following relationship:

$$
\frac{4.62}{k_{\mathrm{obsd}(\mathrm{Cd})}} \leqq t \leqq \frac{0.00995}{k_{\mathrm{obsd}(\mathrm{Zn})}},
$$

where $k_{\mathrm{obsd}(\mathrm{Cd})}$ and $k_{\mathrm{obsd}(\mathrm{Zn})}$ represent the $k_{\mathrm{obsd}}$ values for cadmium(II) and zinc(II), respectively. By introducing the $k_{\text {obsd(Cd) }}$ and $k_{\text {obsd(Zn) }}$ values obtained at each NTA concentration into Eq. (11), the shaking time for the quantitative separation of cadmium(II) from zinc(II) can be calculated. Under the abovementioned experimental conditions $\left(\left[\mathrm{H}_{2} \mathrm{dz}\right]_{\text {org }}=1.0 \times 10^{-3} \mathrm{~mol}\right.$ $\left.\mathrm{dm}^{-3}, \mathrm{pH}=7.0\right)$, Eq. (11) was satisfied when the NTA concentration was more than $5 \times 10^{-3} \mathrm{~mol} \mathrm{dm}^{-3}$. The extraction curves for cadmium(II) and zinc(II) with dithizone in the presence of $1.0 \times 10^{-2} \mathrm{~mol} \mathrm{dm}{ }^{-3}$ NTA are shown in Fig. 5. In 


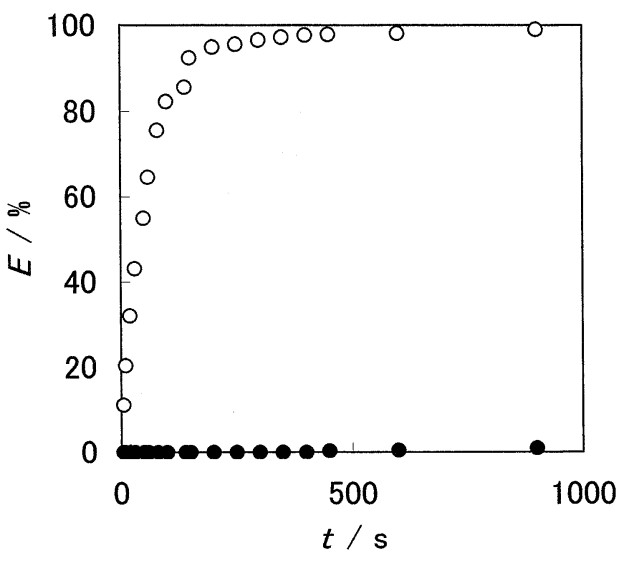

Fig. 5 Plots of extractability (E) for cadmium(II) and zinc(II) against shaking time $(t)$. ( $\mathrm{O})$, cadmium(II); $(\bullet)$, zinc(II). [NTA]: 1.0 $\times 10^{-2} \mathrm{~mol} \mathrm{dm}^{-3} ;\left[\mathrm{H}_{2} \mathrm{dz}\right]_{\text {org }}: 1.0 \times 10^{-3} \mathrm{~mol} \mathrm{dm}^{-3} ; \mathrm{pH}: 7.0$.

this case, Eq. (11) suggests that quantitative separation can be performed at shaking times of 326 from $995 \mathrm{~s}$. The experimental results agree with the prediction, where the quantitative separation of cadmium(II) from zinc(II) is performed within the above range of shaking times.

In conclusion, the addition of NTA is useful for the kinetic separation of cadmium(II) from zinc(II). A quantitative separation can be achieved by single extraction with a shaking time of a few minutes. Kinetic separation using an auxiliary complexing agent is expected to be an effective method for the mutual separation of metal ions.

\section{Acknowledgements}

The authors wish to express their thanks to Miss Yukiko Hosoya, Miss Mai Tanaka, and Miss Miki Koyama for their experimental assistance.

\section{References}

1. H. M. N. H. Irving, "Dithizone", 1977, The Chem. Soc., London.

2. J. Stary, "The Solvent Extraction of Metal Chelates", 1964, Pergamon Press, New York, 42.

3. H. M. N. H. Irving, "Dithizone", 1977, The Chem. Soc., London, 47.

4. H. Kawamoto, H. Itabashi, and M. Nemoto, Anal. Sci., 1995, 11, 289.

5. H. Itabashi, Y. Takazawa, N. Niibe, and H. Kawamoto, Anal. Sci., 1997, 13, 921.

6. H. M. N. H. Irving, "Dithizone", 1977, The Chem. Soc., London, 52.

7. M. Tanaka, "Youbaityusyutu no Kagaku (Solvent Extraction Chemistry, in Japanese)", 1977, Kyouritusyuppan, Tokyo, 56. 